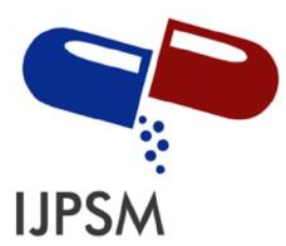

Souvik Basak et al, Int. Journal of Pharmaceutical Sciences and Medicine (IJPSM),

Pharma Middle East Virtual Congress (Dec 07-08, 2020)

www.pharma-middleeast.plenareno.com

ISSN: 2519-9889

Impact Factor: 3.426

\title{
Contaminated Rice, A Silent Psychopharmacological Killer?- A Bio-Molecular Landscape and Possible Solution
}

\author{
Souvik Basak $^{1}$; Moitrayee Chattopadhyay ${ }^{2}$ Gautam Kumar Bagchi $^{3}$ \\ ${ }^{1 *}$ Department of Pharmaceutical Technology, Dr B. C. Roy College of Pharmacy \& Allied Health Sciences, \\ Durgapur, West Bengal, India \\ ${ }^{2}$ Department of Pharmacology, Bengal School of Technology, Sugandha, Chuchura, West Bengal, India \\ ${ }^{3}$ Department of Pharmacology, Techno India College of Pharmacy, Kolkata, West Bengal, India \\ DOI: 10.47760/ijpsm.2020.v05i12.009
}

Rice is a predominant food consumed by more than half of the population in the world. Till date, rice toxins have been predominantly reported as heavy metals such as arsenic, lead or cadmium due to its culture conditions and microbes such as Bacillus cereus or Staphyloccocccus aureus due to its storage conditions; gastric irritations and associated clinical manifestations have been the outcomes of such toxicity. Herein, we have explored the neuropharmacological toxicity of contaminated rice which may be associated with the poor storage of rice feedstock. For example, autoclaving a random sample of contaminated rice at $121^{\circ} \mathrm{C}$ at 14 psi pressure for 15 mins, yielded an extract which resulted in reduced locomotor, depression scoring and muscle relaxant activity in healthy Swiss- albino rats. The identification studies advocated the presence of Stenotrophomonas maltophilia, a gram negative bacillus in it; whose cell extract was revealed to induce such altered neuropharmacological behaviour. FAME guided GC-MS analysis of such extract demonstrated that mono and di-unsaturated fatty acids (UFA) such as 18:1 $\omega 7 \mathrm{c}, 16: 1 \omega 6 \mathrm{c}$, 16:1 $\omega 7 \mathrm{c}$ and 18:2 $\omega 6,9 \mathrm{c}$ long chain fatty acids have been the chief agents probably acting as the toxicants. The in silico analysis revealed binding interactions of UFA with certain bioamine producing enzymes possibly interfering with bioamine production. 


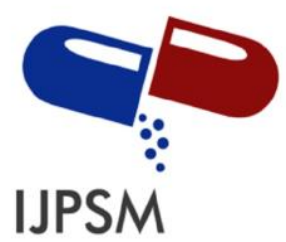

Souvik Basak et al, Int. Journal of Pharmaceutical Sciences and Medicine (IJPSM),

Pharma Middle East Virtual Congress (Dec 07-08, 2020)

www.pharma-middleeast.plenareno.com

ISSN: 2519-9889

Impact Factor: 3.426

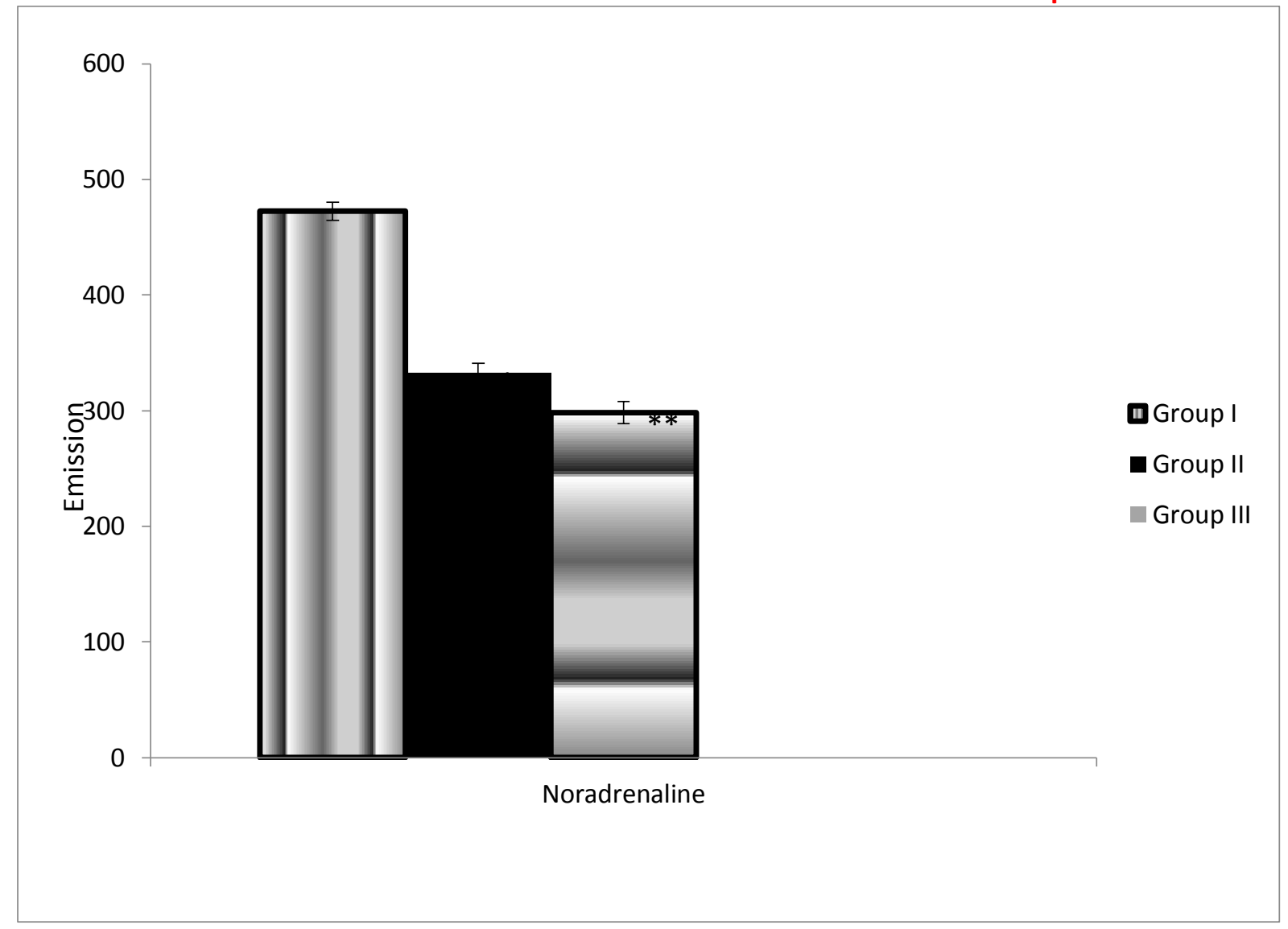

Figure 1: Noradrenaline level in brain after treatment with cell lysate of $S$. maltophilia for 15 days. Group I-Normal saline, Group II- 200 mg/kg, Group III-300 mg/kg

The experimental investigation revealed major bioamines reduction, more depletion occurring with chronic administration of the extract. In furtherance, cytological analysis revealed destruction of neuronal microglial cells by extract treatment with concomitant rise of reactive oxygen species within the cell. The microtomy of brain demonstrated signs of inflammation with leucocyte infiltration and tissue necrosis. 


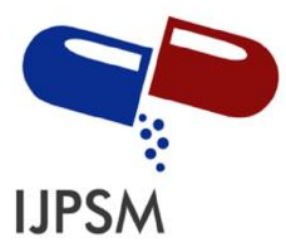

Souvik Basak et al, Int. Journal of Pharmaceutical Sciences and Medicine (IJPSM),

Pharma Middle East Virtual Congress (Dec 07-08, 2020)

www.pharma-middleeast.plenareno.com

ISSN: 2519-9889

Impact Factor: 3.426

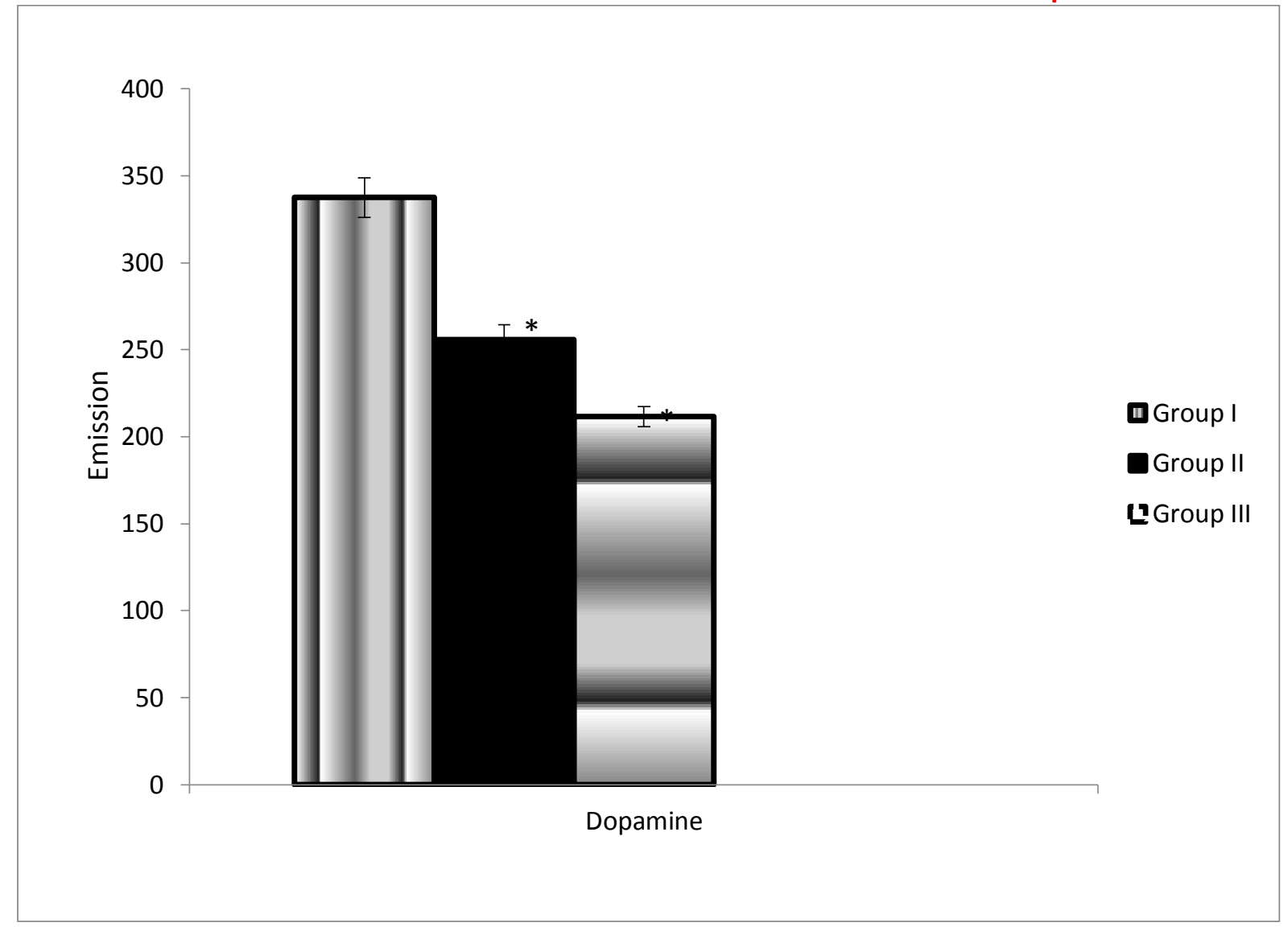

Figure 2: Dopamine level in brain after treatment with cell lysate of $\boldsymbol{S}$. maltophilia for 15 days. Group I-Normal saline, Group II- 200 mg/kg, Group III-300 mg/kg

Possible clinical solution: Administering antibiotics like Minocycline or Cephalosporins which can cross blood brain barrier and kill the microbe. Symptomatic relief: Administer Antidepressants or neuroprotective antioxidants such as Edaravone. 